\title{
Genotoxicology of N-Nitroso Compounds
}




\title{
TOPICS IN CHEMICAL MUTAGENESIS
}

\author{
Series Editor: Frederick J. de Serres \\ National Institute of Environmental Health Sciences \\ Research Triangle Park, North Carolina
}

Volume 1 Genotoxicology of N-Nitroso Compounds

Edited by T. K. Rao, W. Lijinsky, and J. L. Epler

Volume 2 Single-Cell Mutation Monitoring Systems: Methodologies and Applications Edited by Aftab A. Ansari and Frederick J. de Serres

A Continuation Order Plan is available for this series. A continuation order will bring delivery of each new volume immediately upon publication. Volumes are billed only upon actual shipment. For further information please contact the publisher. 


\section{Genotoxicology of N-Nitroso Compounds}

Edited by

\section{T. K. RAO}

Environmental Health Research and Testing, Inc.

Research Triangle Park, North Carolina

\section{W. LIJINSKY}

NCI-Frederick Cancer Research Facility

Frederick, Maryland

and

J. L. EPLER

Oak Ridge National Laboratory

Oak Ridge, Tennessee 
Main entry under title:

Genotoxicology of N-nitroso compounds.

(Topics in chemical mutagenesis; v. 1)

Includes index.

1. Nitroso-compounds - Toxicology-Addresses, essays, lectures. 2. Carcinogenicity testing-Addresses, essays, lectures. 3. Genetic toxicology-Addresses, essays, lectures. 4. Mutagenicity testing-Addresses, essays, lectures. 5. Chemical mutagenesis-Addresses, essays, lectures. I. Rao, T. K., 1946- . II. Lijinsky, W., 1928III. Epler, J. L. IV. Series. [DNLM: 1. Nitroso compounds-Toxicity. 2. Mutagens. 3. Carcinogenesis. QZ 202 G335]

RC268.7.N58G46 1984

DOI $10.1007 / 978-1-4684-4595-4$

(c) 1984 Plenum Press, New York

Softcover reprint of the hardcover 1st edition 1984

A Division of Plenum Publishing Corporation

233 Spring Street, New York, N.Y. 10013

All rights reserved

No part of this book may be reproduced, stored in a retrieval system, or transmitted in any form or by any means, electronic, mechanical, photocopying, microfilming, recording, or otherwise, without written permission from the Publisher 


\section{Contributors}

A. W. Andrews, Program Resources, Inc., and Chemical Carcinogenesis Program, LBI-Basic Research Program, NCI-Frederick Cancer Research Facility, Frederick, Maryland 21701

R. K. Elespuru, Biological Carcinogenesis Program, NCl-Frederick Cancer Research Facility, Frederick, Maryland 21701. Present address: Fermentation Program, NCI-Frederick Cancer Research Facility, Frederick Maryland 21701 .

J. L. Epler, Biology Division, Oak Ridge National Laboratory, Oak Ridge, Tennessee 37830

J. G. Farrelly, Chemical Carcinogenesis Program, NCI-Frederick Cancer Research Facility, Frederick, Maryland 21701

J. B. Guttenplan, Department of Biochemistry, New York University Dental Center, New York, New York 10010

L. I. Hecker, Chemical Carcinogenesis Program, NCI-Frederick Cancer Research Facility, Frederick, Maryland 21701

T. Ho, Biology Division, Oak Ridge National Laboratory, Oak Ridge, Tennessee 37830

A. W. HsIE, Biology Division, Oak Ridge National Laboratory, Oak Ridge, Tennessee 37830

E. Huberman, Argonne National Laboratory, Division of Biological and Medical Research, Argonne, Illinois 60439

C. A. Jones, Argonne National Laboratory, Division of Biological and Medical Research, Argonne, Illinois 60439

W. LiJinsky, Chemical Carcinogenesis Program, NCI-Frederick Cancer Research Facility, Frederick, Maryland 21701

V. D. Mitchell, Genetic Toxicology Branch, Food and Drug Administration, Washington, D.C. 20204 
M. J. Prival, Genetic Toxicology Branch, Food and Drug Administration, Washington, D.C. 20204

T. K. Rao. Biology Division, Oak Ridge National Laboratory, Oak Ridge, Tennessee 37830. Present address: Environmental Health Research and Testing, Inc., Research Triangle Park, North Carolina 27709

J. R. San Sebastian, Biology Division, Oak Ridge National Laboratory, Oak Ridge, Tennessee 37830. Present address: Pharmakon Research International Inc., Waverly, Pennsylvania 18471 


\section{Foreword}

Topics in Chemical Mutagenesis is a new series dedicated to studies in the areas of environmental chemical mutagenesis and genetic toxicology. In this series we will explore some of many topics that are emerging in these rapidly developing fields.

The purpose of the present volume is to attempt to organize and compare the genotoxic properties of the $\mathrm{N}$-nitroso compounds. This is a particularly interesting class of compounds because of the problems encountered with the Salmonella assay of Ames in generating both false positive and false negative results. The battery approach using a number of assay systems seems more appropriate to evaluate chemicals in this class.

Topics to be discussed in other volumes in this series include single-cell mutation monitoring systems, the detection of genetic damage in mammalian germ cells, the mutagenicity of pesticides, problems in monitoring human populations in genetic toxicology, and a glossary of terms in genetic toxicology. All of these books are in various stages of development and should appear within the next few years.

Frederick J. de Serres

Series Editor 


\section{Preface}

During the past ten years there has been an explosive development in the number of short-term tests to predict the biological risks, especially risks of cancer, in exposure to xenobiotic chemicals. The number of published articles in this area has reached many thousands a year and there are several new journals devoted almost entirely to the presentation of the results obtained in these tests. The developers and large-scale users of these tests often rival one another in their claims of validity as predictors of carcinogenicity. Many of the test systems have mutagenesis as the measured end point, and it is frequently forgotten that mutagenesis itself is a biological hazard and that the measurement of a mutagenic risk to man is of equal importance with the estimation of carcinogenic risk. A number of books and review articles have been written about the development and application of short-term assays for mutagenesis-carcinogenesis, but none has focused on the applications of these assays to a single group of well-tested carcinogens sufficiently large and important to be a guide to understanding the complex processes of mutagenesis and carcinogenesis and the relation between them.

Almost three years ago, Dr. F. J. de Serres organized a meeting at the National Institutes of Health that was attended by a number of scientists who had worked, sometimes cooperatively, sometimes alone, in examining the behavior of a single group of compounds, the N-nitroso compounds, in the assay with which they were most familiar. From this group of scientists, all of whom presented interesting data, several volunteered to pool their results in the compilation of a single volume that would be devoted to the comparison of the results obtained with $\mathrm{N}$-nitroso compounds from mainly a single source of consistent chemical quality, and an evaluation of those results as a predictor of one assay system by another, and that would be a means of illuminating the complexity of the mechanisms of biological action of these toxicants. It is this 
volume that we present as an effort to understand the meaning of all of the results, often disparate, that appear in the literature describing the application of all of these assay systems. The conclusions represent a consensus view of these combined efforts and are a beginning for the continuing process of unraveling the mechanisms of genetic toxicology through comparative studies of biological assays, based on a firm foundation of chemical structural relations among $\mathrm{N}$-nitroso compounds.

T. K. Rao

W. Lijinsky

J. L. Epler 


\section{Contents}

Chapter 1. Formation of N-Nitroso Compounds and

Their Significance ............................

WILLIAM LIJINSKY

Chapter 2. N-Nitrosamine Mutagenicity Using the Salmonella/Mammalian-Microsome Mutagenicity

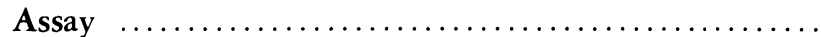

A. W. ANDREWS AND W. LIJINSKY

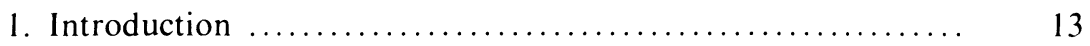

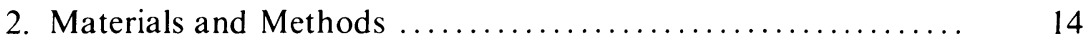

2.1. Chemicals .................................... 14

2.2. Bacterial Strains .............................. 14

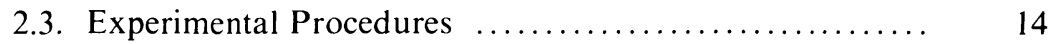

2.4. Preparation of Liver Homogenates ................. 16

3. Mutagenic Activity and Chemical Structure $\ldots \ldots \ldots \ldots \ldots \ldots . . \ldots$

3.1. Cyclic Nitrosamines ........................... $\quad 16$

3.2. Aromatic Nitrosamines and Related Compounds ....... 24

3.3. Acyclic Nitrosamines ........................... 24

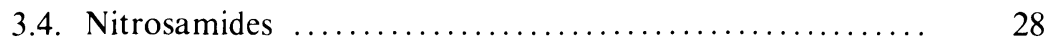

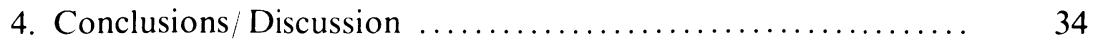

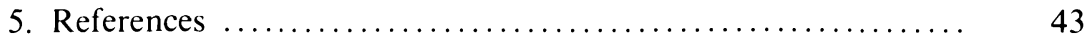


Chapter 3. Structural Basis for Mutagenic Activity of N-Nitrosamines in the Salmonella Histidine

Reversion Assay

T. K. RAO

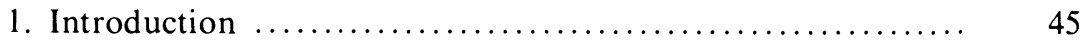

2. Salmonella typhimurium-Histidine Reversion Assay ........ 46

2.1. Bacterial Strains ............................. 46

2.2. Mutagenesis Assay_Procedures .................. 47

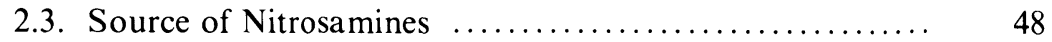

3. Mutagenesis Studies in Salmonella typhimurium ........... 48

3.1. Mechanism of Mutation Induction by Nitrosamines .... 48

3.2. Relationship between Chemical Structure and Mutagenic Activity .................................... 48

3.3. Nitrosamines-Model Compounds for Mutagenesis

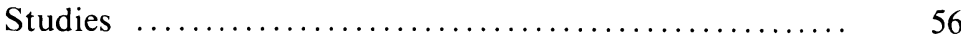

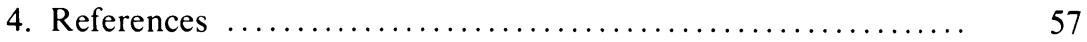

Chapter 4. Effects of $\mathrm{pH}$ and Structure on the Mutagenic Activity of N-Nitroso Compounds ................. JOSEPH B. GUTTENPLAN

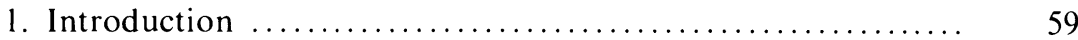

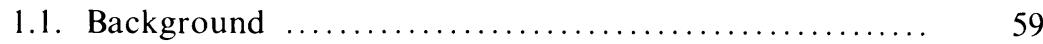

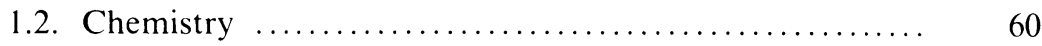

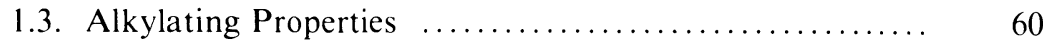

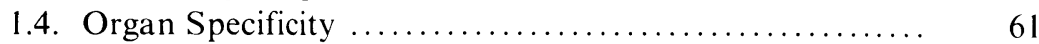

1.5. In Vitro Mutagenesis ............................ 62

1.6. Problems with Assays: Metabolism ................... 62

1.7. DNA Repair ................................. 63

1.8. Permeation into Bacteria ........................ 63

1.9. Optimizing Test Conditions $\ldots \ldots \ldots \ldots \ldots \ldots \ldots \ldots \ldots \ldots \ldots \ldots$

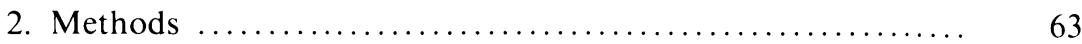

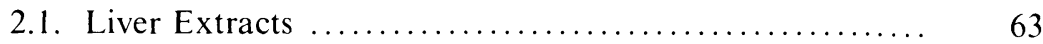

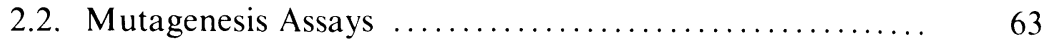

2.3. DMN Demethylase $\ldots \ldots \ldots \ldots \ldots \ldots \ldots \ldots \ldots \ldots \ldots . \ldots \ldots$

2.4. Isolation of DNA and Analysis of Alkylated Bases ...... 63

3. Effects of $\mathrm{pH}$ on Mutagenesis and DNA Alkylation by

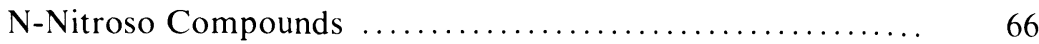

3.1. N-Nitrosamines .............................. 67

3.2. Direct-Acting Compounds $\ldots \ldots \ldots \ldots \ldots \ldots \ldots \ldots \ldots . \ldots 6$ 
3.3. Alkylation of Isolated DNA $\ldots \ldots \ldots \ldots \ldots \ldots \ldots \ldots \ldots \ldots$

3.4. Alkylation of DNA in Salmonella ................... 71

3.5. Possible Explanations: NMU, MNNG ............... 71

3.6. Possible Explanations: N-Nitrosamines .............. 73

3.7. Possible Relevance to Carcinogenesis ................ 73

3.8. Applications to in Vitro Mutagenesis Assays .......... 73

4. Mutagenesis by $\mathrm{N}$-Nitroso- $\mathrm{N}^{\prime}$-nitroso- $\mathrm{N}$-alkylguanidines $\ldots . .74$

4.1. How to Compare Mutagenic Potencies ............... 74

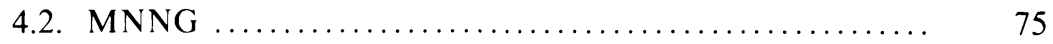

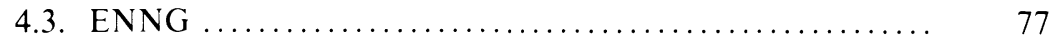

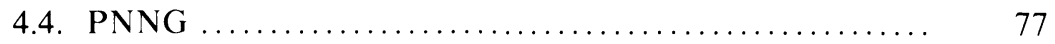

4.5. Comparisons between Mutagens ................... 78

5. Repair of $\mathrm{O}_{6}$-Methylguanine and Its Effect on Mutagenesis $\ldots \quad 78$

5.1. $\mathrm{O}_{6}-\mathrm{MeG}$ and $7-\mathrm{MeG}$ in Salmonella DNA .............. 78

5.2. Threshold in $\mathrm{O}_{6}$-MeG Formation $\ldots \ldots \ldots \ldots \ldots \ldots \ldots . .79$

5.3. Attempt to Observe Repair of $\mathrm{O}_{6}-\mathrm{MeG} \ldots \ldots \ldots \ldots \ldots \ldots . . \ldots$

5.4. Dependence of Mutagenesis on $\mathrm{O}_{6}-\mathrm{MeG} \ldots \ldots \ldots \ldots . . .60$

6. Alternate Mechanisms of Mutagenesis by N-Nitroso

Compounds ..................................... 81

7. Mutagenesis by a Series of "Weakly Mutagenic"

N-Nitrosamines: Effects of Structure $\ldots \ldots \ldots \ldots \ldots \ldots \ldots \ldots . \ldots 2$

7.1. Conditions $\ldots \ldots \ldots \ldots \ldots \ldots \ldots \ldots \ldots \ldots \ldots \ldots \ldots \ldots \ldots, \quad 82$

7.2. Results: Di-N-alkylnitrosamines and Related

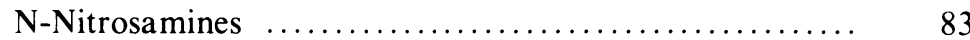

7.3. $\beta$-Substituted N-Nitrosamines $\ldots \ldots \ldots \ldots \ldots \ldots \ldots \ldots . \ldots . \ldots . \ldots . \ldots$

7.4. $\alpha$-Substituted N-Nitrosamines $\ldots \ldots \ldots \ldots \ldots \ldots \ldots \ldots . \ldots . \ldots . \ldots$

8. Correlation between Mutagenic Potencies and Carcinogenic Activities of Some N-Nitroso Compounds ................ 86

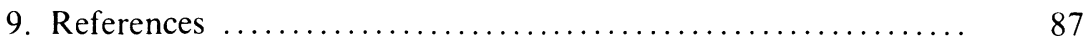

Chapter 5. Induction of Bacteriophage Lambda by N-Nitroso

Compounds ..................................

Rosalie K. ELESPURU

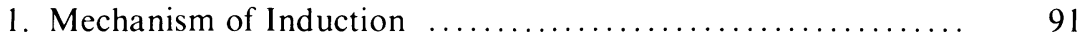

2. Genetics and Methodology ......................... 91

3. Factors Affecting Induction by Nitroso Compounds ........ 93

3.1. Bacterial Strain .............................. 93

3.2. Source and Amount of Activating Enzymes ........... 95

3.3. Media ..................................... 97

3.4. Kinetic Parameter ............................. 97 


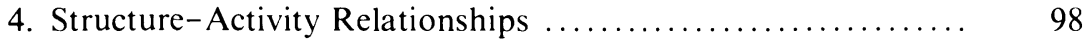

5. Relationships between Mutagenicity, Carcinogenicity, and Phage Induction

6. Mechanism of Action of Nitroso Compounds as Inducers of Bacteriophage Lambda ................................ 111

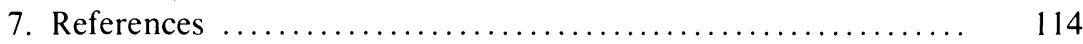

Chapter 6. The Relationship between the Carcinogenicity and Mutagenicity of Nitrosamines in a Hepatocyte-Mediated Mutagenicity Assay ........................... Carol A. Jones and Eliezer Huberman

Chapter 7. Mutagenic Activity of Nitrosamines in Mammalian Cells: Study with the CHO/HGPRT and Human Leukocyte SCE Assays .......................... Ti Ho, JuAn R. SAN SEbastian, AND ABRAHAM W. HSIE

1. Introduction

2. Mutagenic Activity of Eight Nitrosamines in the $\mathrm{CHO} / \mathrm{HGPRT}$ Assay

2.1. The $\mathrm{CHO} / \mathrm{HGPRT}$ Assay

2.2. Mutagenic Activity of Nitrosodimethylamine as Studied in the CHO/HGPRT Assay

2.3. Mutagenicity of Eight Nitrosamines in the $\mathrm{CHO} / \mathrm{HGPRT}$ Assay and Its Correlation with Carcinogenicity ..........

3. Mutagenic Activity of 15 Nitrosamines in the Human Leukocyte SCE Assay

3.1. Sister-Chromatid Exchanges (SCE) in the Human Leukocyte Culture System

3.2. Induction of SCE by 15 Cyclic Nitrosamines in Human Leukocytes in Vitro and Its Correlation with Carcinogenicity

4. Summary and Concluding Remarks $\ldots \ldots \ldots \ldots \ldots \ldots \ldots \ldots, 142$

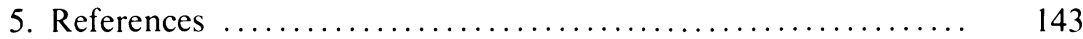


Chapter 8. Dimethylnitrosamine Demethylase and the Mutagenicity of Dimethylnitrosamine: Effects of Rodent Liver Fractions and Dimethylsulfoxide

Michael J. PRIVAL AND

VALERIE D. MrTCHELL

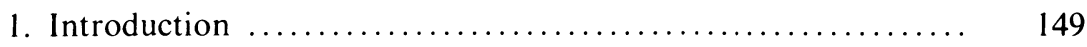

2. Materials and Methods ............................ 150

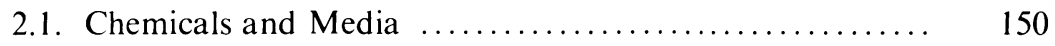

2.2. Mutagenesis Assays ......................... 151

2.3. Preparation of S-9 Fractions and Microsomes ......... 151

2.4. Enzyme Assays ............................ 152

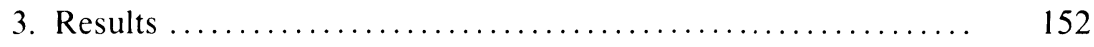

3.1. Kinetics of DMN Demethylase in Hamster Liver S-9 ... 152

3.2. Correlation of Mutagenic and Enzyme Activities ....... 152

3.3. Effects of Mixing Liver Fractions from Different

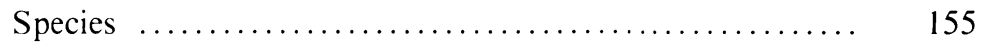

3.4. Cytosol Requirement for Mutagenicity of DMN ...... 157

3.5. Effects of Dimethylsulfoxide .................... 159

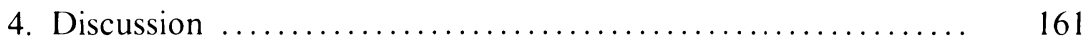

4.1. Apparent $K_{m}$ Values and Regulation of DMN

Demethylase $\ldots . \ldots \ldots \ldots \ldots \ldots \ldots \ldots \ldots \ldots \ldots . \ldots \ldots 1$

4.2. Microsomal Inhibitor of DMN Mutagenesis ......... 161

4.3. Cytosolic Activator of DMN Mutagenesis ........... 162

4.4. Inhibition by Dimethylsulfoxide ................ 163

4.5. Screening Chemicals with Hamster Liver S-9 ......... 163

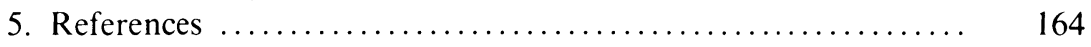

Chapter 9. The Relationship between Metabolism and Mutagenicity of Two Cyclic Nitrosamines ................... JAMES G. FARRELLY AND LANNY I. HECKER

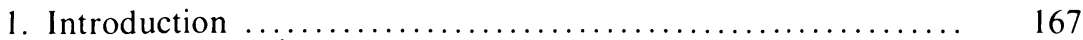

2. Materials and Methods .............................. 169

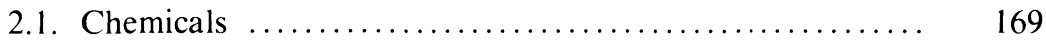

2.2. Preparation of Microsomes ..................... 169

2.3. Assay for Nitrosopyrrolidine Metabolism .......... 170

2.4. Large-Scale Production of Metabolites .............. 170

2.5. Mutagenesis Assay of NPYR with E. coli WU 3610

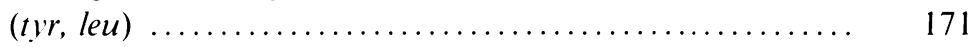

2.6. Mutagenesis Assay of Nitrosohexamethyleneimine ..... 171 


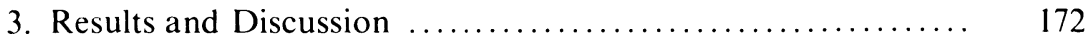

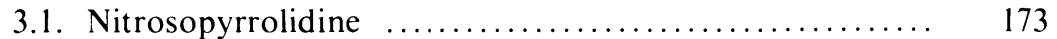

3.2. Nitrosohexamethyleneimine ..................... 180

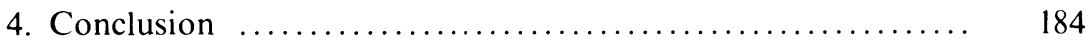

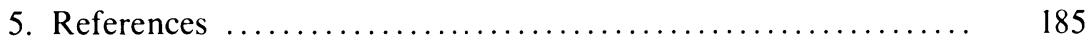

Chapter 10. Structure-Activity Relations in Carcinogenesis by

N-Nitroso Compounds ........................ 189

WILLIAM LJINSKY

1. Introduction ....................................... 189

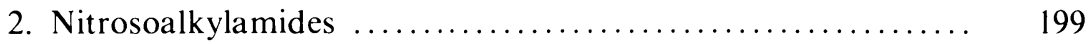

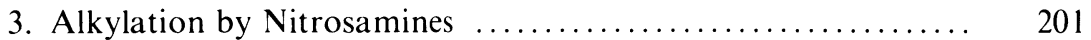

4. Nitrosomethylalkylamines (X) ...................... 204

5. Substituted Acyclic Nitrosamines $\ldots \ldots \ldots \ldots \ldots \ldots \ldots \ldots \ldots . \ldots 207$

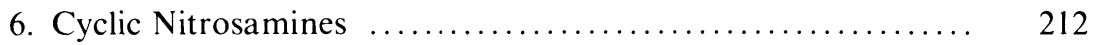

7. Substituted Cyclic Nitrosamines ....................... 215

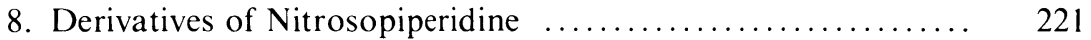

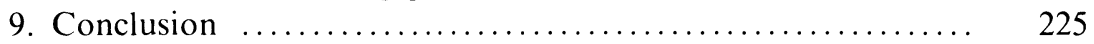

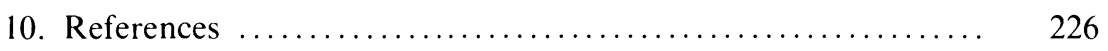

Chapter 11. Comparison of Mutagenic and Carcinogenic Properties: A Critique $\ldots \ldots \ldots \ldots \ldots \ldots \ldots \ldots \ldots \ldots \ldots \ldots . \ldots \ldots$

W. LIJINSKY, J. L. EPLER, AND T. K. RAO

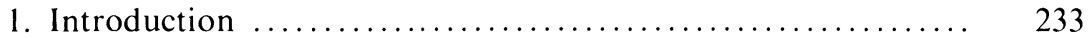

2. Tabular Summation and Integration of Results ........... 235

2.1. Selection of Nitroso Compounds for the Comparative Study ........................................ 235

2.2. In Vitro Assays ............................... 235

2.3. In Vivo Assay ............................... 236

3. Comparison of Mutagenic End Points .................. 236

4. Relationship between Short-Term Test Results and

Carcinogenicity ................................ 245

4.1. Qualitative Relationships ....................... 245

4.2. Quantitative Relationships ...................... 257

5. Precautions in Interpretation and Extrapolation ........... 259

6. References .................................... 260

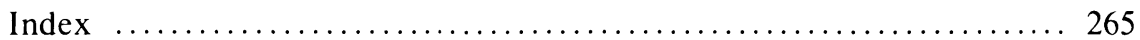

